\title{
Methyl Esterase 1 (StMES1) Is Required for Systemic Acquired Resistance in Potato
}

\author{
Patricia M. Manosalva, ${ }^{1}$ Sang-Wook Park, ${ }^{1}$ Farhad Forouhar, ${ }^{2}$ Liang Tong, ${ }^{2}$ William E. Fry, ${ }^{3}$ and \\ Daniel F. Klessig ${ }^{1}$
}

\begin{abstract}
${ }^{1}$ Boyce Thompson Institute for Plant Research, Tower Road, Ithaca, NY 14853, U.S.A.; ${ }^{2}$ Department of Biological Sciences, Northeast Structural Genomics Consortium, Columbia University, New York, NY 10027, U.S.A.; ${ }^{3}$ Department of Plant Pathology and Plant-Microbe Biology, Cornell University, Ithaca, NY 14853, U.S.A.
\end{abstract}

Submitted 27 January 2010. Accepted 28 April 2010.

\begin{abstract}
Whether salicylic acid (SA) plays a role in systemic acquired resistance (SAR) signaling in potato is currently unclear because potato, unlike tobacco and Arabidopsis, contains highly elevated levels of endogenous SA. Recent studies have indicated that the $\mathrm{SA}$ derivative methyl salicylate (MeSA) serves as a long-distance phloem-mobile SAR signal in tobacco and Arabidopsis. Once in the distal, uninfected tissue of these plant species, MeSA must be converted into biologically active $S A$ by the esterase activity of SA-binding protein 2 (SABP2) in tobacco or members of the AtMES family in Arabidopsis. In this study, we have identified the potato ortholog of tobacco SABP2 (StMES1) and shown that the recombinant protein converts MeSA to SA; this MeSA esterase activity is feedback inhibited by $\mathrm{SA}$ or its synthetic analog, 2, 2, 2, 2'-tetra-fluoroacetophenone (tetraFA). Potato plants (cv. Désirée) in which StMES1 activity was suppressed, due to either tetraFA treatment or silencing of StMES1 expression, were compromised for arachidonic acid (AA)-induced SAR development against Phytophthora infestans. Presumably due to the inability of these plants to convert MeSA to SA, the SAR-defective phenotype correlated with elevated levels of MeSA and reduced expression of pathogenesis-related $(P R)$ genes in the untreated distal tissue. Together, these results strongly suggest that SAR signaling in potato requires StMES1, its corresponding MeSA esterase activity, and MeSA. Furthermore, the similarities between SAR signaling in potato, tobacco, and Arabidopsis suggest that at least certain SAR signaling components are conserved among plants, regardless of endogenous SA levels.
\end{abstract}

In nature, plants are attacked by several different kinds of pathogens, including bacteria, fungi, oomycetes, and viruses. As a result, plants have evolved active mechanisms for defending themselves against pathogen attack. Some of these plant immune responses have been extensively studied and classified according to the molecular mechanism for pathogen recognition (Chisholm et al. 2006; Jones and Dangl 2006). Pathogenassociated molecular pattern (PAMP)-triggered immunity

Corresponding author: Daniel F. Klessig; Fax: +1-607-254-6779; E-mail: dfk8@cornell.edu

Current address of S.-W. Park: Virginia Bioinformatics Institute, Virginia Polytechnic Institute and State University, Blacksburg, VA 24061, U.S.A.

* The $e$-Xtra logo stands for "electronic extra" and indicates that four supplementary figures and two supplementary tables are published online.
(PTI) is activated by the recognition of molecules that are common to many classes of microbes (PAMPs); it is largely responsible for conferring basal disease resistance following infection by a virulent pathogen. In comparison, effector-triggered immunity (ETI), previously defined as resistance $(R)$ gene-mediated resistance, is activated by direct or indirect recognition of specific effector molecules from the pathogen. ETI results in a more rapid and robust induction of defense responses than occurs during PTI and often culminates in a hypersensitive response (HR) at the infection site (Greenberg and Yao 2004; Chisholm et al. 2006; Jones and Dangl 2006). Both forms of resistance have been associated with physiological changes in the inoculated leaf, including early responses such as the generation of reactive oxygen species, ion fluxes, and the accumulation of salicylic acid (SA), as well as late responses such as the accumulation of antimicrobial compounds, including phytoalexins, and the induction of defense-related genes, such as the pathogenesis-related $(P R)$ genes. In addition to these responses, ETI is usually associated with the development of systemic acquired resistance (SAR), a physiological state whereby the plant's innate defenses are activated or potentiated systemically, making the plant more resistant to subsequent biotic challenges (Durrant and Dong 2004; Vlot et al. 2008a). Induced resistance pathways are regulated by key signaling hormones such as SA, jasmonic acid (JA), and ethylene (ET), which cause substantial changes in gene expression and are involved in complex crosstalk (Glazebrook 2005).

Many studies have demonstrated that SA plays a critical role in resistance signaling pathways (Raskin 1992; Dempsey et al. 1999; Durrant and Dong 2004; Vlot et al. 2009). Exogenous application of SA enhances disease resistance and induces $P R$ gene expression in a wide variety of plant species. Moreover, endogenous SA levels were found to increase in both the inoculated and distal leaves of pathogen-infected tobacco and cucumber plants, and this increase preceded or paralleled $P R$ gene induction and SAR development (Malamy et al. 1990; Métraux et al. 1990; Vlot et al. 2009). Confirmation that SA is a critical component of the SAR signaling pathway came from analyses of transgenic tobacco and Arabidopsis expressing the bacterial $N a h G$ gene, which encodes the SA-degrading enzyme salicylate hydroxylase $(\mathrm{SH})$. These plants, which failed to accumulate SA after pathogen infection, displayed reduced resistance against avirulent and virulent pathogens and did not develop SAR or express $P R$ genes in their distal leaves (Vlot et al. 2009). However, grafting studies demonstrated that SA was not the long-distance mobile signal for SAR. Despite suppressed SA levels, Tobacco mosaic virus (TMV)-infected $N a h G$ transgenic rootstocks were able to generate and transmit 
a signal that induced SAR in wild-type (WT) scions (Vernooij et al. 1994).

A few candidate mobile SAR signals have been proposed. Several studies have implicated a role for lipids or lipidderived molecules in SAR signaling (Maldonado et al. 2002; Nandi et al. 2004; Chaturvedi et al. 2008). Recently, the mobile metabolite azelaic acid was proposed to be a mobile signal for SAR (Jung et al. 2009). In addition, Park and associates (2007) demonstrated that the SA derivative methyl salicylate (MeSA) is a long-distance mobile signal for SAR in tobacco. Based on these findings, a working model for MeSA signaling was proposed in which MeSA accumulates in the primary infected tissue after TMV infection and is translocated through the phloem to the distal uninfected tissue. Once in the uninfected tissue, MeSA is converted to its biologically active form, SA, by the MeSA esterase activity of the SA-binding protein 2 (NtSABP2). The characterization of NtSABP2 orthologs in Arabidopsis, designated AtMES, argues that $\mathrm{MeSA}$ and its corresponding MeSA esterase activity also play a critical role in SAR signaling in Arabidopsis (Vlot et al. 2008b).

Compared with tobacco and Arabidopsis, which contain very low levels of SA prior to infection, some plant species, such as potato and rice, constitutively accumulate high levels of SA (Coquoz et al. 1995; Silverman et al. 1995). Indeed, the basal level of SA in potato is approximately 40- to 100-fold higher than that found in tobacco or Arabidopsis (Coquoz et al. 1995). For this reason, it is currently unclear whether the MeSA signaling model proposed for tobacco and Arabidopsis applies to potato and other plants containing high endogenous SA levels. Most of the studies aimed at elucidating SAR signaling and the role of SA during local and distal resistance in potato have been performed using the oomycete Phytophthora infestans, causal agent of late blight disease. Basal defense responses are activated following infection with this hemibiotrophic pathogen but they are not sufficient to arrest $P$. infestans growth in the inoculated leaf. However, SAR against $P$. infestans can be induced by preinoculating potato plants with Pseudomonas syringae (Kombrink et al. 1996) or Phytophthora cryptogea (Strömberg and Brishammar 1991). Inoculation of potato cv. Bintje with a complex race of $P$. infestans also induces SAR against a secondary challenge with a virulent race of $P$. infestans (Strömberg and Brishammar 1991). Alternatively, SAR in potato can be induced by treatment with PAMPs such as eicosapentaenoic acid or arachidonic acid (AA); AA is a major fatty acid present in the mycelial cell membrane and spores of $P$. infestans (Cohen et al. 1991; Coquoz et al. 1995).

Analyses of potato responding to these SAR-inducing treatments have yielded conflicting results regarding the role of SA as a defense signal. The combined findings that i) exogenous SA does not induce SAR, although it does induce $P R$ gene expression (Coquoz et al. 1995), and ii) SA levels rise locally but not systemically after induction of SAR by AA (Coquoz et al. 1995; Yu et al. 1997) suggest that SA is not an important defense regulator in potato. By contrast, other evidence suggests that SA is involved in defense signaling. For example, SA or its functional analog, benzothiadiazole, induces $P R$ gene expression in potato (Kombrink et al. 1996; Navarre and Mayo 2004), and $P R$ gene expression and protein activity have been shown to increase in both the infected tissue and, to a lesser extent, the uninfected distal tissue of potato cv. Datura plants inoculated with a virulent isolate of $P$. infestans (Schröder et al. 1992). In addition, younger leaves of potato, which contain higher SA levels than older leaves, are more resistant to infection by $P$. infestans (Coquoz et al. 1995). Potato cultivars containing higher endogenous levels of SA also exhibit greater field resistance than cultivars with lower SA levels (Coquoz et al. 1995). Furthermore, SA-deficient $N a h G$ potato plants fail to develop AA-induced SAR against $P$. infestans (Yu et al. 1997). SA also appears to be required for basal defense (PTI) in potato against $P$. infestans (Halim et al. 2007, 2009). Transgenic $N a h G$ potato plants were more susceptible to $P$. infestans and were impaired for $P R$ gene induction and callose deposition at early time points after infection (Halim et al. 2007). Recent data suggest that PAMP responses in potato require not only SA but also JA and, in contrast to Arabidopsis, these molecules act in the same signal transduction pathway (Halim et al. 2009).

In the current study, we have identified a potato ortholog of NtSABP2, Solanum tuberosum methyl esterase 1 (StMES1), and assessed its possible role in SAR signaling. Similar to NtSABP2 and AtMES9, StMES1 displayed SA-inhibitable MeSA esterase activity in vitro. Moreover, a synthetic version of StMES1 complemented the SAR-defective phenotype of SABP2-silenced tobacco plants (Kumar and Klessig 2003). Through inhibition studies and an RNAi silencing approach, StMES1 was shown to be required for AA-mediated induction of SAR against a virulent isolate of $P$. infestans in potato. Thus, our results argue that SAR signal transduction and perception in potato share some common components with the corresponding processes in Arabidopsis and tobacco. Given the high endogenous SA levels, future studies will likely identify other aspects of the SAR signaling pathway that diverge between these plant species. However, the possibility that broad-spectrum resistance can be engineered in potato, the world's fourth largest crop, by manipulating SA and MeSA levels (and thereby increasing the effectiveness of SAR induction) may yield significant practical applications for engineering disease resistance and, thereby, improving food security.

\section{RESULTS}

\section{Identification and sequence analysis of the putative ortholog of SABP2 in potato.}

The full-length cDNA sequence of NtSABP2 (Kumar and Klessig 2003) was used as a query to perform Basic Local Alignment Search Tool (BLAST) analysis against a potato expressed sequence tag (EST) database to identify potato homologs of NtSABP2. SABP2's putative potato ortholog (GenBank no. CK270870.1) was identified based on its strong sequence homology to NtSABP2. Unlike the Arabidopsis ortholog AtMES9 (Vlot et al. 2008b), which shares only $46 \%$ identity with NtSABP2, CK270870.1 shares 74\% identity and $85 \%$ similarity with NtSABP2 at the protein level.

The full-length sequence of the potato $S A B P 2$ (StMES1) was cloned via reverse-transcription polymerase chain reaction (RT-PCR) using cDNA from uninfected potato tissue and sequenced. The sequenced 786 bp of StMES1 cDNA encodes a protein of 262 amino acids (aa) with an expected molecular weight of $29.83 \mathrm{kDa}$. StMES1 shares $75.6 \%$ identity and $85.1 \%$ similarity with NtSABP2 at the amino acid level; it also contains the catalytic triad $\left(\mathrm{Ser}^{82}\right.$, $\mathrm{His}^{240}$, and $\left.\mathrm{Asp}^{211}\right)$ that forms part of the active site pocket (Fig. 1). These three residues are highly conserved among SABP2 orthologs from Arabidopsis (AtMES) and poplar (PtSABP2-1 and -2) (Vlot et al. 2008b; Zhao et al. 2009), as well as closely related members of the $\alpha / \beta$ hydrolase superfamily (Forouhar et al. 2005). StMES1 also contains 12 of the 15 aa identified in NtSABP2 that interact with SA (Fig.1) (Forouhar et al. 2005). By contrast, AtMES9 contains only five of these 15 residues, with conservative substitutions at five additional sites (Fig. 1). The strong sequence homology and conservation of critical SA-binding residues in StMES1 and NtSABP2 suggest that these two proteins share similar biochemical properties. 
StMES1 displays MeSA esterase activity and is competitively inhibited by $\mathrm{SA}$.

To determine the biochemical properties of StMES1, its corresponding full-length cDNA was expressed in Escherichia coli. C-terminal His ${ }_{6}$-tagged StMES1 was successfully expressed as a 29-kDa protein (Supplementary Fig. 1). Purified recombinant StMES1 readily converted MeSA to SA. Under steady-state conditions, StMES1 hydrolyzed MeSA with an apparent $\mathrm{K}_{\mathrm{m}}$ value of $57.9 \mu \mathrm{M}$ and $\mathrm{V}_{\max }$ value of 0.29 $\mu \mathrm{mol} / \mathrm{min}^{-1} \mathrm{mg}^{-1}$ (Fig. 2A). Consistent with our previous demonstration that SA binds the active site pocket of NtSABP2 and thereby inhibits its MeSA esterase activity $\left(\mathrm{K}_{\mathrm{i}}=16.4 \mu \mathrm{M}\right)$ (Du and Klessig 1997; Forouhar et al. 2005; Park et al. 2009), SA competitively inhibited StMES1's MeSA esterase activity with a $K_{i}$ of $67 \mu \mathrm{M}$ (Fig. 2B).

\section{StMES1 complements SAR deficiency} in $S A B P 2$-silenced tobacco.

To establish that StMES1 is an ortholog of NtSABP2, complementation analysis was performed using SAR-deficient, $S A B P 2$-silenced tobacco (Kumar and Klessig 2003). The possibility that StMES1 expression would be silenced by the endogenous NtSABP2-silencing construct was precluded by using a synthetic version of StMES1 (StMES1syn); this strategy was used previously to successfully express synthetic versions of NtSABP2 (SABP2syn2) and its Arabidopsis ortholog (AtMES9syn) in SABP2-silenced tobacco (Kumar et al. 2006; Vlot et al. 2008b). StMES1syn shares 57\% nucleotide identity with NtSABP2 and encodes a WT StMES1 protein fused at its C-terminus with an myc tag (Supplementary Fig. 2).
Following construction of stable $S A B P 2$-silenced tobacco plants expressing StMES1syn (NtSABP2-silenced + StMES1syn) driven by the $\beta$-estradiol-inducible XVE promoter system (Zuo et al. 2000), StMES1syn expression and the SAR phenotype were monitored. StMES1syn expression was induced by treating the distal, uninfected tissue with $\beta$-estradiol 1 day after a primary infection with TMV. RT-PCR revealed that StMES1syn transcripts increased from undetectable levels at the time of $\beta$-estradiol induction to readily observable levels by 1 or 6 days posttreatment (Fig. 3A). The synthetic protein, monitored by Western blot analysis using antibodies against the myc tag, was detected only after $\beta$-estradiol induction (data not shown). Thus, the synthetic protein was successfully expressed and its expression was tightly regulated by the XVE promoter. As a positive control, XVE-induced expression of AtMES9syn was monitored in SABP2-silenced tobacco expressing the AtMES9syn transgene. $\beta$-Estradiol treatment induced AtMES9syn transcript accumulation; however, the low levels of transcripts detectable at 0 time indicated that regulation of this transgene was somewhat leaky (Fig. 3A). This finding was previously noted by Vlot and associates (2008b). In comparison, $\beta$-estradiol treatment did not alter the constitutive expression of $N t S A B P 2$ in WT plants and it did not induce $N t S A B P 2$ expression in any of the $S A B P 2$-silenced tobacco lines.

To monitor SAR in these plants, the sizes of TMV-induced primary and secondary lesions were compared. WT plants developed SAR, as indicated by a $50.1 \%$ reduction in the size of secondary lesions compared with primary lesions (Fig. 3B). By contrast, SAR was compromised in the $S A B P 2$-silenced
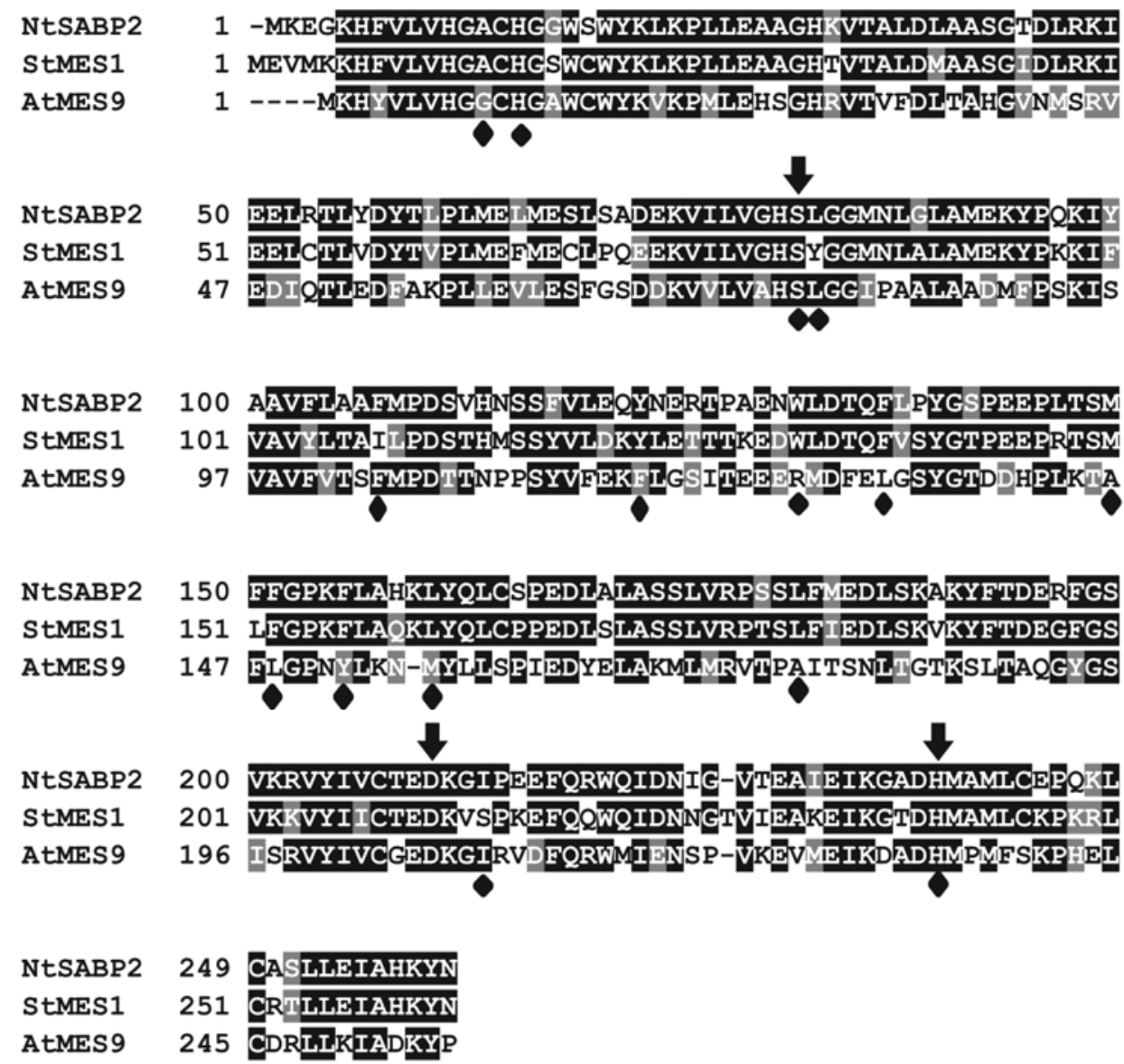

Fig. 1. Multiple sequence alignment of StMES1, tobacco SABP2 (NtSABP2), and an Arabidopsis ortholog of SABP2 (AtMES9). Identical residues are shaded in black and similar residues in gray. The catalytic triad residues are indicated by arrows, and residues that contact salicylic acid are indicated with black diamonds. 
tobacco line, because only a $14.6 \%$ reduction was observed (Fig. 3B). This value is within the previously reported range displayed by SAR-deficient plants (Park et al. 2007; Vlot et al. 2008b). StMES1syn and AtMES9syn fully complemented the SAR deficiency in the $S A B P 2$-silenced tobacco line, because the primary lesions were reduced 57.4 and $59.1 \%$, respectively, compared with the sizes of the respective primary lesions (Fig. 3B; Supplementary Table 1). Together, these results suggest that StMES1 is a true ortholog of NtSABP2 and AtMES9.

\section{Tetra-fluoroacetophenone inhibits StMES1 esterase activity and blocks \\ AA-induced SAR development in potato.}

In 2009, Park and associates reported that 2, 2, 2, 2'-tetrafluoroacetophenone (tetraFA) specifically inhibited the MeSA esterase activity of NtSABP2 and AtMES9 in vitro. TetraFA treatment of uninfected distal tissue also compromised SAR in pathogen-infected tobacco and Arabidopsis plants (Park et al. 2009). Using the three-dimensional crystal structure of NtSABP2 complexed with SA (Forouhar et al. 2005), the interaction between tetraFA and the active site of NtSABP2 was modeled (PDB accession code: 1Y71). To extend these studies, we assessed the ability of StMES1 to bind SA or tetraFA. Given the strong sequence homology between StMES1 and

\section{A}
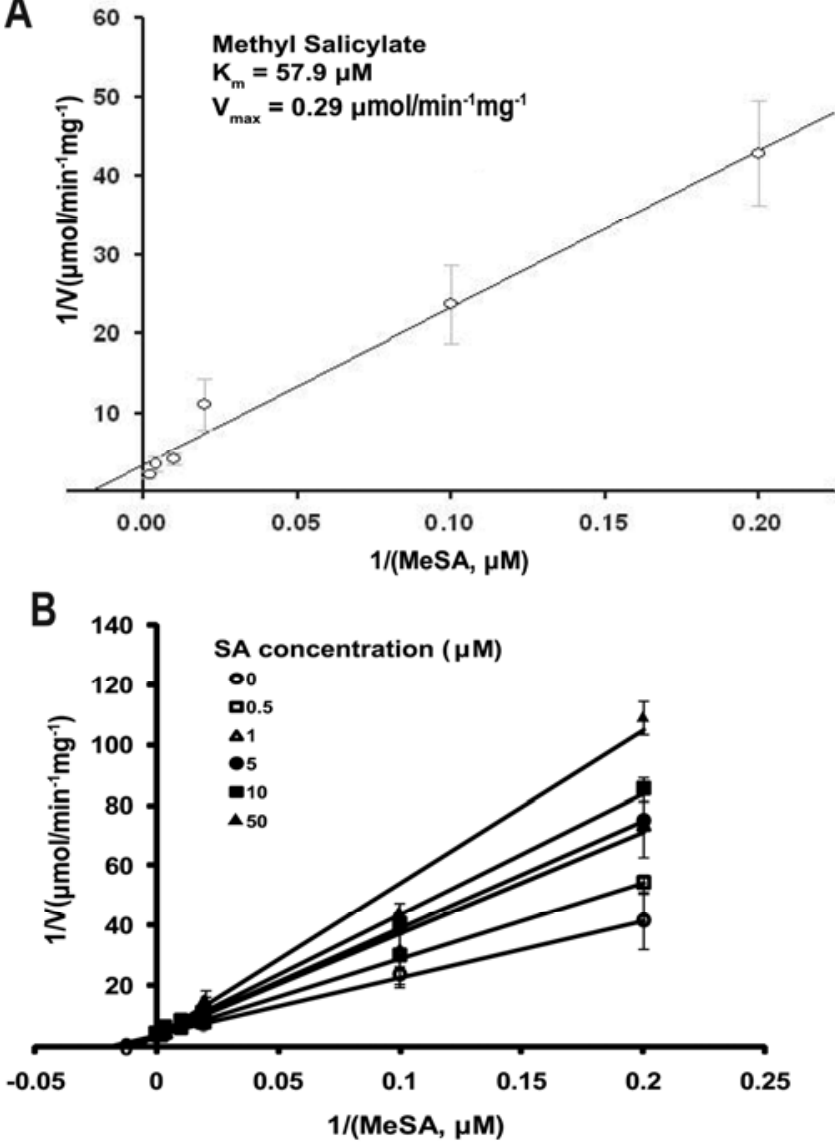

Fig. 2. Biochemical characterization of StMES1 from potato. A, Lineweaver-Burk plot showing the kinetic parameters of the StMES1 esterase using methyl salicylate (MeSA) as a substrate; error bars are shown as the standard deviation $(n=3)$. B, Inhibition of StMES1 MeSA esterase activity by salicylic acid (SA). Lines represent a global fit of all data $(n=$ $3)$ to the equation for competitive inhibition. Initial velocities were calculated at $0 \mu \mathrm{M}$ (open circles), $0.5 \mu \mathrm{M}$ (open squares), $1 \mu \mathrm{M}$ (open triangles), $5 \mu \mathrm{M}$ (closed circles), $10 \mu \mathrm{M}$ (closed squares), and $50 \mu \mathrm{M}$ (closed triangles) SA.
NtSABP2 $(85 \%)$ and the similar biochemical properties of both proteins, including MeSA esterase activity and SA feedback inhibition, the tobacco SABP2 crystal structure was used as a reference for constructing three-dimensional models of StMES1 complexed with SA or tetraFA. Similar to NtSABP2, stereoview representations of StMES1 showed that SA or tetraFA can be accommodated in the active site pocket of StMES1, although tetraFA must be rotated $180^{\circ}$ in comparison with SA (Fig. 4).

To determine the biological relevance of this interaction between StMES1 and tetraFA, we tested whether tetraFA inhibited StMES1's MeSA esterase activity in vitro. Increased concentrations of tetraFA were found to inhibit the MeSA esterase activity of recombinant StMES1 with a half maximal inhibitory concentration $\left(\mathrm{IC}_{50}\right)$ value of $0.6 \mathrm{mM}$ (Fig. $5 \mathrm{~A}$ ). The role of MeSA and StMES1 in planta was then assessed by applying tetraFA to the upper untreated tissue of potato and monitoring the ability of AA to induce SAR against a virulent isolate of $P$. infestans. We used potato (S. tuberosum L.) cv. Désirée, which has no known $R$ genes (R0) but has a moderate field resistance against $P$. infestans (Coquoz et al. 1995). As expected, AA treatment of the lower leaves of WT potato induced SAR in the upper untreated leaves; SAR was manifested by an approximately twofold reduction in both the size of the blighted area and the concentration of $P$. infestans sporangia compared with control plants that received a water (mock) treatment on their lower leaves (Fig. 5B and C). However, when tetraFA was sprayed on the upper untreated leaves of WT potato before challenge with $P$.infestans, SAR was compromised. Regardless of whether the tetraFA-treated plants received a prior treatment with AA or water, they exhibited similar levels of disease symptoms and sporangia concentration (Fig. 5B and C). TetraFA treatment did not produce any secondary effects in potato, because plants treated with water and sprayed with tetraFA showed levels of pathogen growth similar to those of control plants treated only with water (Fig. 5B and C).

\section{Silencing StMES1 compromises SAR in potato.}

The tetraFA inhibitor studies strongly argue that StMES1 and MeSA are required for SAR in potato; this likelihood was confirmed by assessing SAR in StMES1-silenced potato. The first 473 bp of the StMES1 cDNA sequence were used to generate an RNAi construct. Following stable transformation, we identified 10 independent lines of Désirée plants in which StMES1 was completely silenced (Fig. 6A). The ability of these StMES1-silenced lines to mount AA-induced SAR against $P$. infestans was then tested. In WT plants, AA treatment led to SAR against $P$. infestans, as manifested by a twofold reduction in the size of the blighted area and sporangia concentration compared with water-treated control plants (Fig. 6B and C). By contrast, SAR was compromised in 9 of the 10 StMES1-silenced lines, because AA treatment did not reduce the severity of late blight symptoms (Fig. 6B and C; Supplementary Fig. 3A). The only exception was StMES1-silenced line RNAi52, in which the blighted area was reduced somewhat after AA treatment, although not to the extent observed in AA-treated WT plants $(P<0.05)$. Because StMES1 was completely silenced in all 10 lines, it is unclear why varying levels of SAR suppression and pathogen responses were observed. However, the observation that WT potato plants exhibit highly variable levels of SA accumulation and $P R$ gene expression (Navarre and Mayo 2004) raises the possibility that some of the silenced lines have a higher background level of SAR compared with others. Alternatively, the differing levels of SAR suppression might be due to the effect of an unidentified StMES gene or genes in potato, which could be differentially co-silenced in the 10 StMES1-silenced lines. 


\begin{tabular}{|c|c|c|c|c|}
\hline \multirow{2}{*}{ A Genotype } & \multirow{2}{*}{ Wild Type } & \multirow{2}{*}{$\begin{array}{l}\text { NtSABP2- } \\
\text { silenced }\end{array}$} & \multicolumn{2}{|c|}{ NtSABP2-silenced plus } \\
\hline & & & AtMES9syn & StMES1syn \\
\hline \multicolumn{5}{|l|}{$\begin{array}{l}\text { Gene } \\
\text { expression }\end{array}$} \\
\hline Transgene & & & $-x-\infty$ & -8 \\
\hline \multicolumn{5}{|l|}{$N t S A B P 2$} \\
\hline \multirow{2}{*}{$\begin{array}{l}\text { EF1a } \\
\text { dp treatment }\end{array}$} & $-2=$ & $-\infty-$ & $-\infty-\infty$ & $\mathrm{cos}=$ \\
\hline & $\begin{array}{lll}0 & 1 & 6\end{array}$ & $\begin{array}{lll}0 & 1 & 6\end{array}$ & $\begin{array}{lll}0 & 1 & 6\end{array}$ & $\begin{array}{lll}0 & 1 & 6\end{array}$ \\
\hline \multicolumn{5}{|c|}{ Lesion size $(\mathrm{mm})$} \\
\hline $1^{\circ}$ infection & $2.81 \pm 0.4$ & $2.56 \pm 0.4$ & $2.51 \pm 0.5$ & $2.88 \pm 0.4$ \\
\hline $2^{\circ}$ infection & $1.4 \pm 0.5$ & $2.18 \pm 0.5$ & $1.03 \pm 0.4$ & $1.23 \pm 0.4$ \\
\hline Reduction & $50.1 \%$ & $14.6 \%$ & $59.1 \%$ & $57.4 \%$ \\
\hline
\end{tabular}

Fig. 3. StMES1 complements the systemic acquired resistance-deficient phenotype of SABP2-silenced tobacco. A, Synthetic versions of AtMES 9 and StMES1 (AtMES9syn and StMES1syn, respectively) were expressed under control of a $\beta$-estradiol inducible promoter in $S A B P 2$-silenced tobacco. Transcript levels for StMES1syn, AtMES9syn, endogenous SABP2 (NtSABP2), and elongation factor $1 \alpha$ (EFl $\alpha$ ) (internal control) were determined by reversetranscription polymerase chain reaction (RT-PCR) using gene-specific primers. Wild-type and transgenic tobacco lines received a primary $\left(1^{\circ}\right)$ inoculation with Tobacco mosaic virus (TMV); 1 day later, distal leaves were treated with $\beta$-estradiol. Samples for RT-PCR analysis were collected at the time of $\beta$-estradiol treatment ( 0 days post [dp] treatment) and at 1 and $6 \mathrm{dp}$ treatment. B, Systemic leaves were subjected to the secondary $\left(2^{\circ}\right)$ inoculation with TMV $6 \mathrm{dp}$ estradiol treatment $\left(7 \mathrm{dp} 1^{\circ}\right.$ inoculation). Lesion sizes were measured on the TMV-inoculated leaves of the indicated plants at $5 \mathrm{dp} 1^{\circ}$ or $2^{\circ}$ TMV infection. The mean \pm standard deviation was derived from 50 to 60 lesions per leaf using three leaves that had received a $1^{\circ}$ inoculation or two leaves that had received a $2^{\circ}$ inoculation. Pictures were taken at $5 \mathrm{dp} 1^{\circ}$ and $2^{\circ} \mathrm{TMV}$ infection. Lesion sizes (mm) are indicated above each picture and the percent reduction in size of $2^{\circ}$ lesions compared with $1^{\circ}$ lesions is indicated at the bottom. This complementation experiment was done three times with similar results.
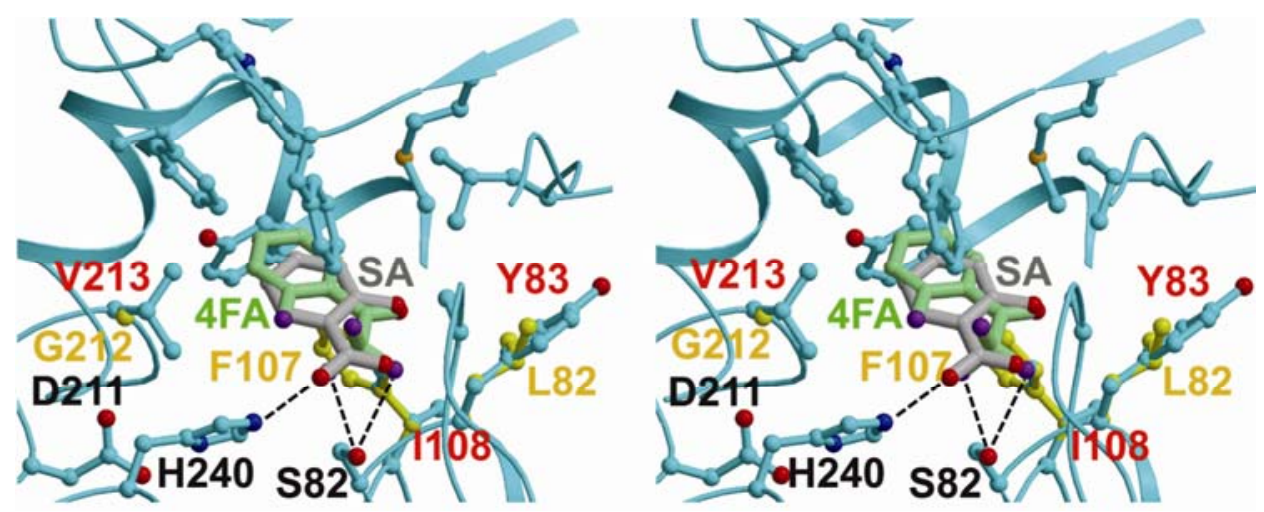

Fig. 4. Model of the active site pocket of StMES1 and the binding modes of 2, 2, 2, 2'-tetrafluoroacetophenone (4FA) compared with salicylic acid (SA). The SA (gray) and 4FA (green) binding modes are shown; the catalytic triad residues (Ser82, Asp211, and His240) are labeled in black. Hydrogen bonds are indicated by dashed lines. The three amino acid substitutions in potato (V213, I108, and Y83, labeled in red) compared with tobacco SABP2 (G212, F107, and L82, labeled in yellow) are depicted as yellow ball-and-stick representations. 
StMES1 silencing increases MeSA levels

and attenuates $P R$ gene induction after $A A$ treatment.

If StMES1 functions in SAR signaling by converting MeSA to SA in the distal leaves, AA-treated StMES1-silenced potato would be expected to accumulate elevated levels of MeSA but reduced levels of SA and $P R$ gene expression in the upper untreated leaves. To test this possibility, the levels of SA, SA glucoside (SAG) (a biologically inactive conjugate of $\mathrm{SA}$ ), $\mathrm{MeSA}$, or $P R$ gene expression were monitored in the AAtreated and upper untreated leaves at 0,24 , and $144 \mathrm{~h}$ posttreatment (hpt). These time points were chosen because i) $P R$ gene transcripts accumulate in the distal leaves of $P$. infestansinoculated potato by $24 \mathrm{~h}$ postinoculation (Schröder et al. 1992), and ii) the SAR assay is performed by inoculating upper untreated leaves with $P$. infestans $144 \mathrm{~h}$ after AA treatment of lower leaves. In WT potato, the levels of SA, SAG, and
MeSA, as well as expression of $P R-1$ and $P R-2$ ( $\beta$-glucanase), increased in the AA-treated leaves by $24 \mathrm{hpt}$ and, generally, remained at that level out to 144 hpt (Fig. 7). Note that the majority of total SA is in the form of SAG. Mock treatment did not induce SA or MeSA accumulation in the treated tissue, indicating that these elevated levels were specific to AA treatment (Supplementary Fig. 4). In the upper untreated tissue, the levels of SA, SAG, and MeSA were elevated at 24 and $144 \mathrm{hpt}$ compared with $0 \mathrm{hpt}$; this correlated with the distal expression of $P R$ genes (Fig. 7). Again, the mock treatment resulted in little or no rise in the amount of SA or MeSA, indicating that the increases were due to AA treatment. In the RNAi25::StMES1 plants, the level of MeSA both before and after AA treatment was significantly higher than that in WT plants in both the treated and untreated tissue (Fig. 7B). By contrast, the basal and induced level of SAG in both the treated and untreated tis-
A

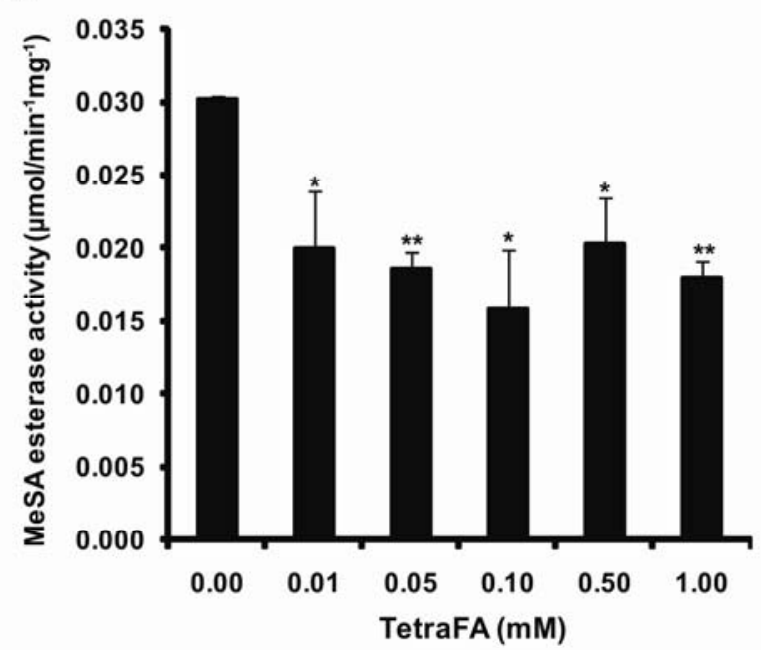

B
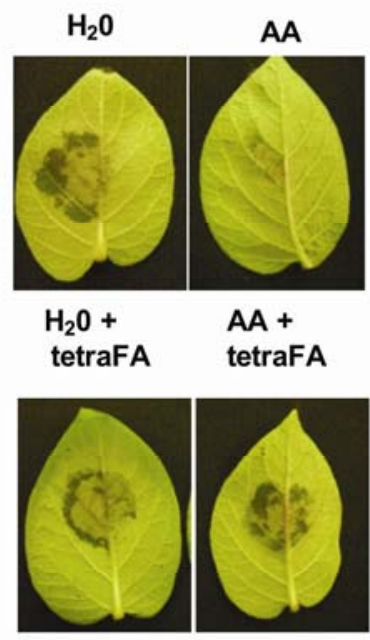

C
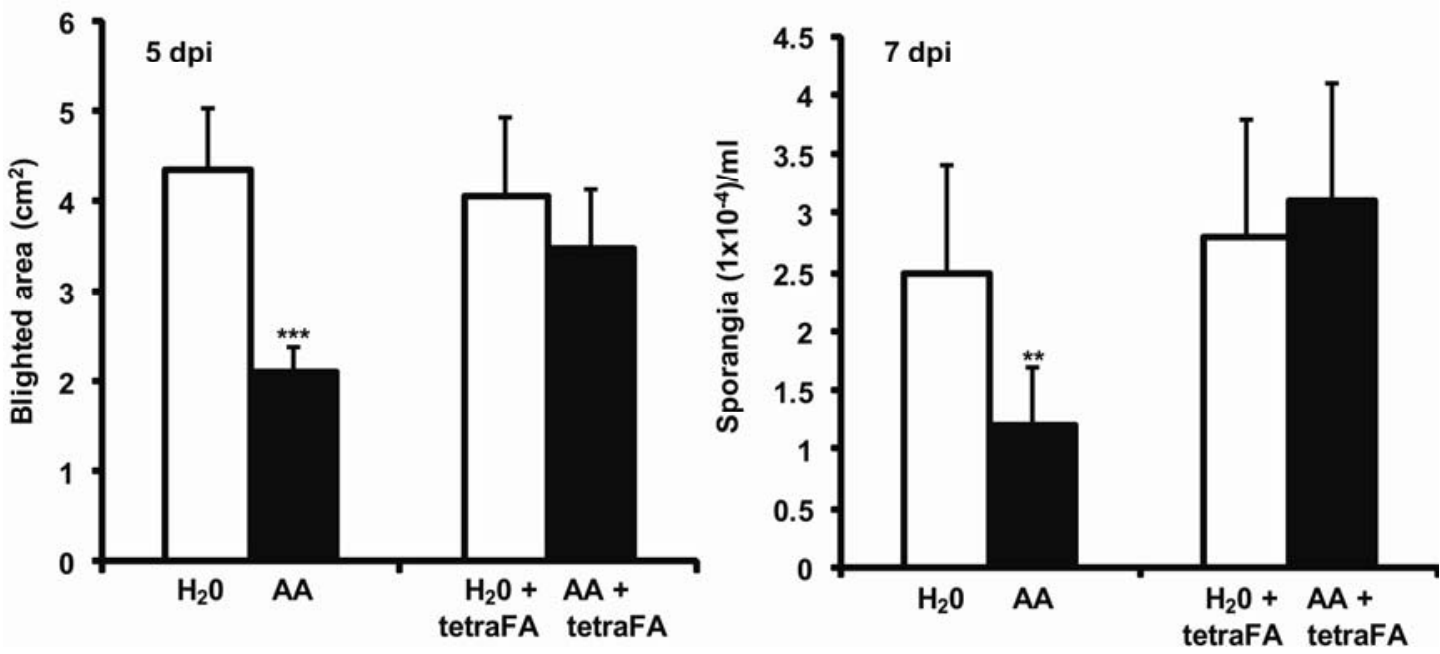

Fig. 5. 2, 2, 2, 2'-Tetra-fluoroacetophenone (tetraFA) inhibits the methyl salicylate (MeSA) esterase activity of StMES1 in vitro and blocks systemic acquired resistance (SAR) development. A, Inhibition of recombinant StMES1 esterase activity by tetraFA in vitro was determined using $0.25 \mathrm{mM}$ MeSA as the substrate and increasing concentrations of tetraFA $(0.01$ to $1 \mathrm{mM})$. Asterisks indicate statistically significant differences $(*$ and $* *$ indicate $P<0.05$ and 0.005 , respectively, student $t$ test) between the enzymatic activity detected in the presence or absence of tetraFA at each concentration. B and $\mathbf{C}$, Inhibition of SAR development by tetraFA. Three potato leaves per plant were sprayed with either water $\left(\mathrm{H}_{2} \mathrm{O}\right)$ or arachidonic acid (AA) at $1.5 \mathrm{mg} / \mathrm{ml} ; 24 \mathrm{~h} \mathrm{after} \mathrm{spraying}$, the leaf immediately above was treated with tetraFA or buffer (control) for 6 days. Leaflets from tetraFA-treated or buffer-treated leaves were detached and inoculated with Phytophthora infestans (US-11) (5,000 sporangia/ml). B, Pictures of the blighted area after P. infestans inoculation were taken at 5 days postinoculation (dpi). C, Disease symptoms were measured by size of the blighted area $\left(\mathrm{cm}^{2}\right)$ at $5 \mathrm{dpi}$ and by the number of sporangia per milliliter at 7 dpi. Inoculated leaflets corresponding to control plants $\left(\mathrm{H}_{2} \mathrm{O}\right.$, and $\mathrm{H}_{2} \mathrm{O}+$ tetraFA) are shown as white bars, and leaflets from AA and AA + tetraFA plants as black bars. Data in C correspond to the pictures in B. Error bars are shown as the standard deviation corresponding to four plants per treatment and two leaflets per plant; this experiment was done twice with similar results. Asterisks indicate statistically significant differences (*** and $* *$ indicate $P<0.0001$ and 0.005 , respectively, student $t$ test) between the disease symptoms (blighted area and sporangia numbers) of plants treated with water to those in plants treated with AA. 
sue of RNAi25::StMES1 plants was reduced compared with the WT (Fig. 7A). SA levels in the AA-treated and distal tissues of RNAi25::StMES1 plants also were suppressed at certain times posttreatment. In the treated leaves, SA levels were comparable with those in WT plants $(P=0.1)$ at $24 \mathrm{hpt}$ but they, along with the level of $P R$ gene expression, were significantly reduced by 144 hpt $(P=0.01)$. In comparison, SA levels and $P R$ gene expression in the untreated leaves were substantially reduced at $24 \mathrm{hpt}(P<0.0001)$ but were closer to WT levels at 144 hpt $(P=0.1)$ (Fig. 7A and C).

\section{DISCUSSION}

Here, we describe the identification of StMES1 from potato and demonstrate that it shares similar biochemical properties with its tobacco and Arabidopsis orthologs. Like NtSABP2 and several members of the Arabidopsis AtMES family, recombinant StMES1 exhibits esterase activity toward MeSA, and this activity is feedback inhibited by SA or the SA analog, tetraFA (Forouhar et al. 2005; Vlot et al. 2008b; Park et al. 2009). However, the $K_{m}$ and $K_{i}$ values of StMES1 (57.9 and 67 $\mu \mathrm{M})$ are seven and four times higher, respectively, than those of NtSABP2 (Forouhar et al. 2005; Park et al. 2009). The higher kinetic parameters for StMES1 may correlate with differences in endogenous SA levels, because we and others have observed that potato contains substantially higher levels of SA than tobacco (Coquoz et al. 1995; Yu et al. 1997). Supporting this possibility, the $\mathrm{K}_{\mathrm{m}}$ values of two NtSABP2 orthologs (PtSABP2-1 and PtSABP2-2) from black cottonwood (Zhao et al. 2009), another species that contains high endogenous SA levels, are similar to that of StMES1. Despite the differing kinetic parameters for StMES1 and NtSABP2, the basal (approximately 120 to $200 \mathrm{ng} / \mathrm{gFW}$ ) and induced (approximately 270 to $400 \mathrm{ng} / \mathrm{gFW}$ ) levels of MeSA in potato and tobacco are comparable (Park et al. 2007).

The combined demonstrations that StMES1syn expression complements the SAR-defective phenotype of $S A B P 2$-silenced tobacco and that AA-induced SAR is compromised in tetraFAtreated and StMES1-silenced potato strongly suggest that StMES1 plays a critical role in the SAR signaling process. The loss of SAR in StMES1-silenced lines correlates with elevated levels of MeSA in the AA-treated and upper untreated leaves and reduced systemic levels of SA, SAG, and $P R$ gene expression compared with the upper untreated leaves of AA-treated WT plants. Similar to this result, the SAR-defective phenotype of $S A B P 2$-silenced tobacco is associated with elevated levels of MeSA and reduced levels of SA and $P R$ gene expression in the distal uninfected leaves (Park et al. 2007; S. W. Park and D. F. Klessig, unpublished data). Arabidopsis underexpressing multiple AtMES genes also are compromised for SAR and accumulate elevated levels of MeSA in their distal leaves (Vlot et al. 2008b). Collectively, these results are consistent with our
A

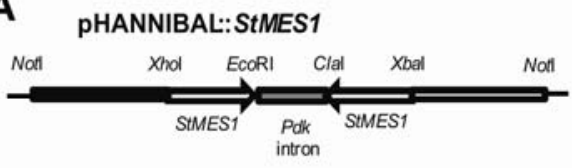

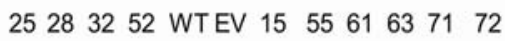

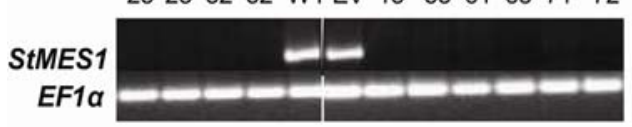

C

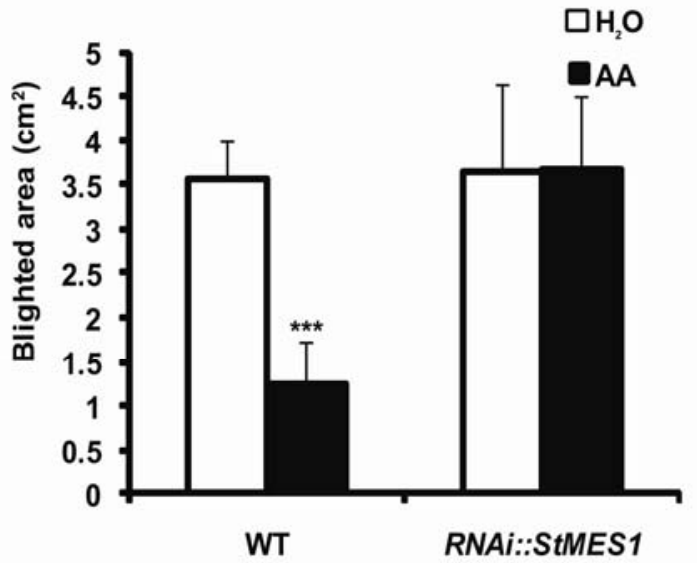

B
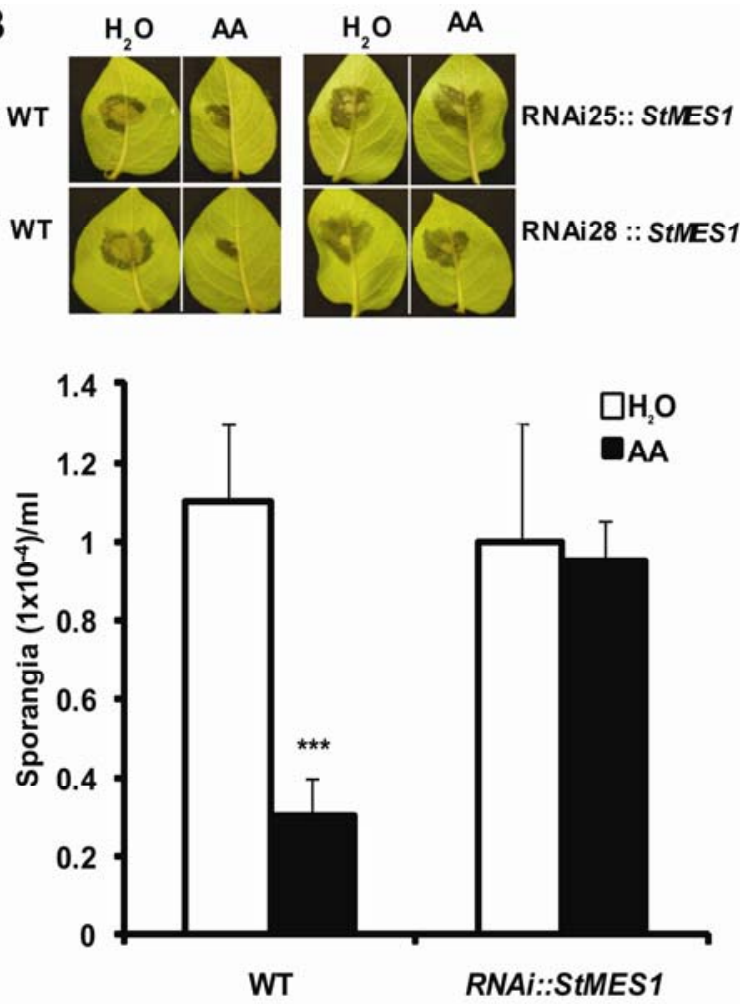

Fig. 6. Silencing StMES1 in potato compromised arachidonic acid (AA)-induced systemic acquired resistance against Phytophthora infestans. A, Ten transgenic potato lines expressing an RNAi construct with the first 473 bp of potato StMES1 were selected and screened for StMES1 silencing, along with wildtype (WT) and empty vector (EV) controls, by reverse transcription-polymerase chain reaction using gene-specific primers. Elongation factor $1 \alpha($ EF $1 \alpha)$ was amplified as an internal control. $\mathbf{B}$ and $\mathbf{C}$, Three potato leaves from WT and StMES1-silenced plants were sprayed with either water $\left(\mathrm{H}_{2} \mathrm{O}\right)$ or AA at 1.5 $\mathrm{mg} / \mathrm{ml} ; 6$ days after spraying, the leaflets immediately above the sprayed leaves were detached and tested for their response to infection by $P$. infestans $(5,000$ sporangia/ml). B, Pictures of the blighted area after P. infestans inoculation were taken at 5 days postinoculation (dpi) in WT and StMES1-silenced potato; two independent transgenic plants are shown (RNAi25 and RNAi28). C, Disease symptoms were measured based on the size of the blighted area ( $\mathrm{cm}^{2}$ ) at 5 dpi and the number of sporangia per milliliter at 7 dpi. Inoculated leaflets corresponding to WT and StMES1-silenced plants sprayed with water $\left(\mathrm{H}_{2} \mathrm{O}\right)$ are shown as white bars, and leaflets from WT and StMES1-silenced plants sprayed with AA as black bars. Error bars for the WT are shown as standard deviation (SD) corresponding to five plants per treatment and two leaflets per plant; the error bars for the StMES1-silenced plants are shown as SD of four RNAiindependent lines (RNAi32, RNAi25, RNAi52, and RNAi28), two plants per line per treatment, and two leaflets per plant; this experiment was done twice with similar results. Asterisks indicate statistically significant differences $(* * *=P<0.0001$, student $t$ test) between the disease symptoms (blighted area and sporangia numbers) of WT plants treated with water to those in WT plants treated with AA. 
model that the MeSA esterase activity of StMES1 and its orthologs is required in the distal leaves to convert MeSA, which is transported from the treated or pathogen-inoculated leaves, into SA, which then activates or potentiates defense responses leading to SAR development. Moreover, the similar phenotypes of plants lacking these MeSA esterases argues that SAR in potato is activated via a similar mechanism to that reported in tobacco and Arabidopsis (Park et al. 2007; Vlot et al. 2008b). It should be noted that the higher $\mathrm{K}_{\mathrm{i}}$ of StMES1 compared with that of NtSABP2 was not expected to affect SAR development in the complementation assay because StMES1syn was specifically expressed in the upper, uninoculated leaves of the $S A B P 2$-silenced tobacco. Our previous studies in tobacco suggest that the $K_{i}$ value for inhibition is only critical in the primary infected tissue. SA-mediated inhibition of NtSABP2's MeSA esterase activity is critical in the infected leaves to allow
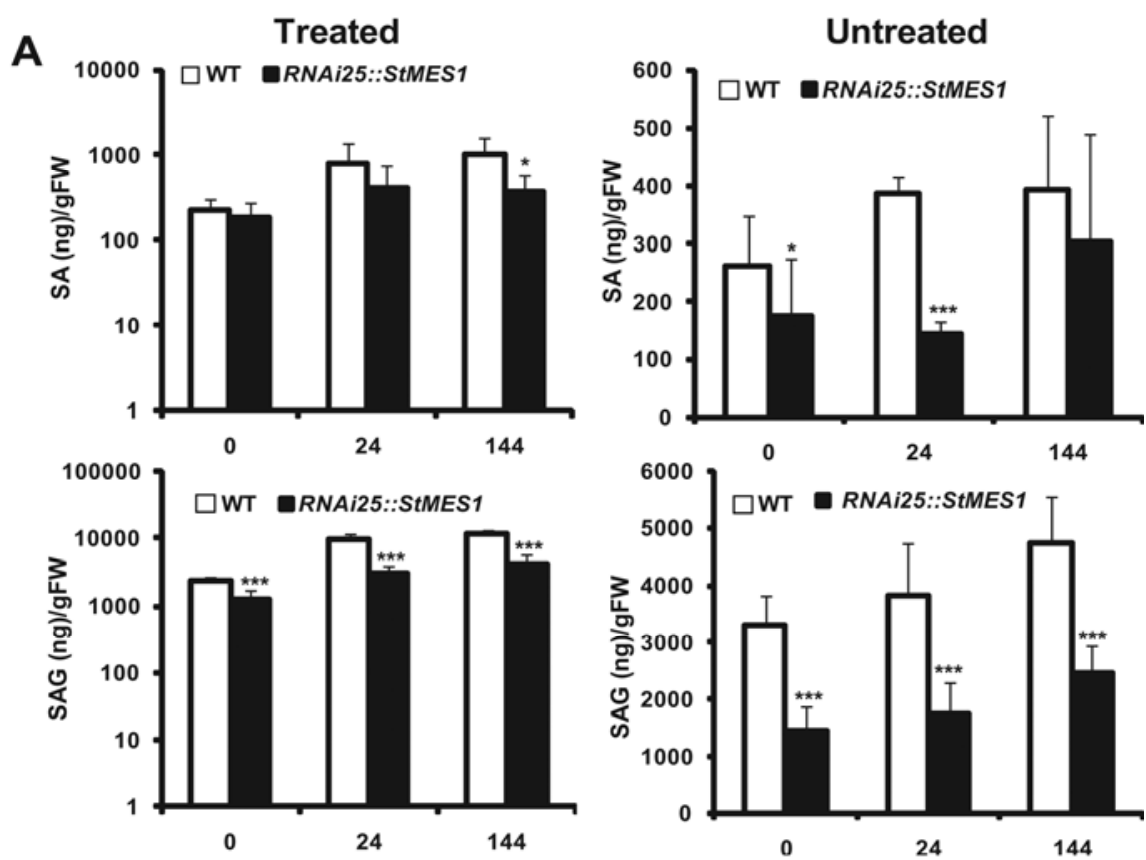

B
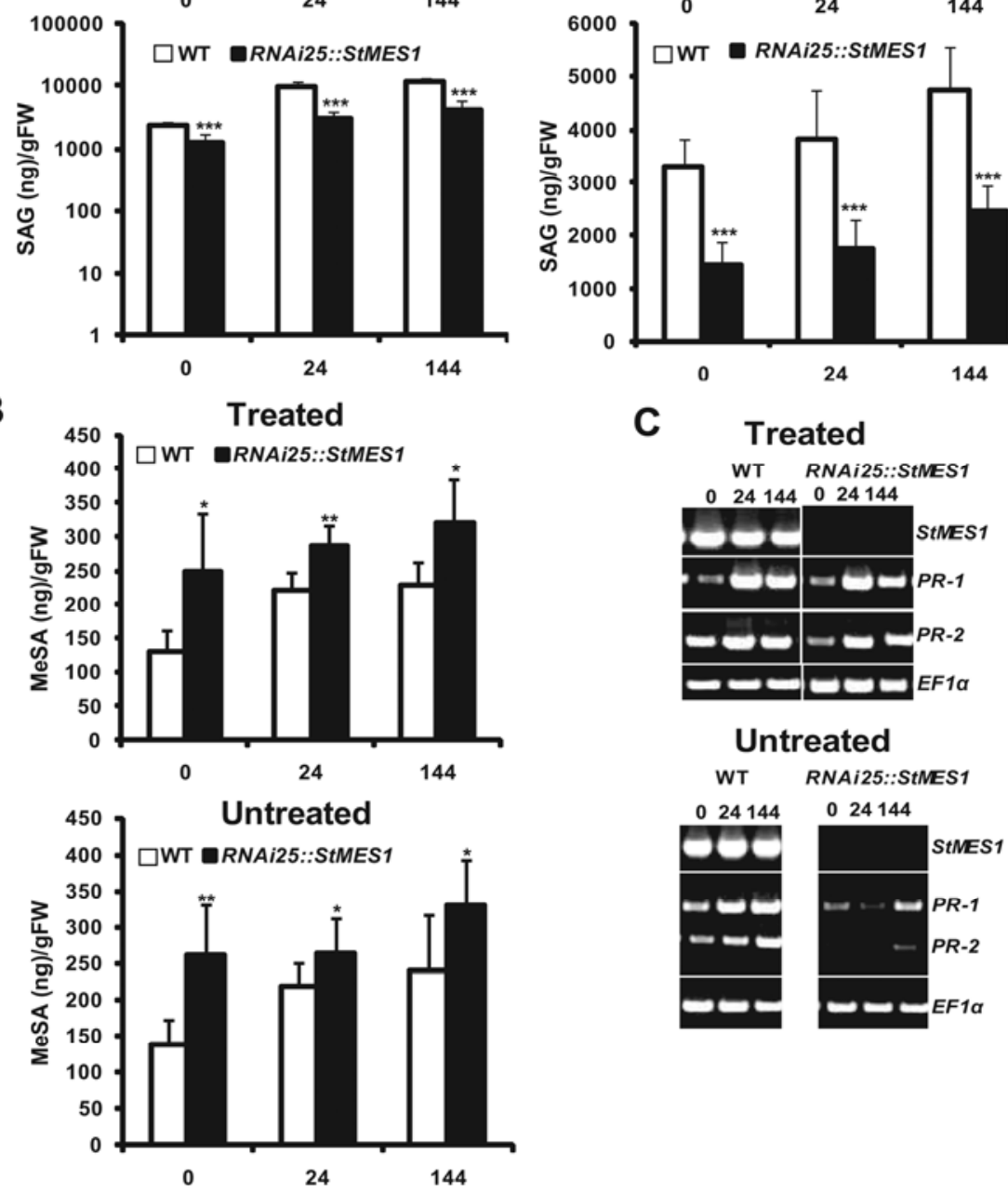

Fig. 7. Kinetics of salicylic acid (SA), SA glucoside (SAG), and methyl salicylate (MeSA) accumulation and pathogenesis-related (PR) gene expression after arachidonic acid (AA) treatment of wild-type (WT) or RNAi25::StMES1-silenced potato. A, SA and SAG were measured in the treated (sprayed with AA) and the untreated tissue directly above at 0,24 , and $144 \mathrm{~h}$ posttreatment (hpt) with AA in WT and RNAi25::StMES1-silenced plants. Note that the level of SA and SAG in the AA-treated tissue is presented on a $\log$ scale. In the treated leaves of WT and RNAi25::StMES1 silenced plants, no statistically significant difference in SA levels $(P=0.1)$ was observed at $24 \mathrm{hpt}$. B, MeSA accumulation was measured in the treated and untreated tissue at 0,24 , and $144 \mathrm{hpt}$ with AA in WT and RNAi25::StMES1-silenced plants. C, PR gene expression after AA treatment was assessed in the treated and untreated tissue of WT and RNAi25::StMES1 plants at 0, 24, and 144 hpt by reverse transcription-polymerase chain reaction using gene-specific primers. Elongation factor $1 \alpha$ (EF1 $\alpha$ ) was used as an internal control. Tissue for the quantification of SA, SAG, MeSA, and $P R$ gene expression was obtained from the same experiment; error bars in A and B represent the standard deviation of three technical replicates for each measurement from two leaves per two plants per time point per genotype for three independent experiments. Asterisks in A and B indicate statistically significant differences $(*, * *$, and $* * *$ indicate $P<0.05,0.005$, and 0.0001 , respectively, student $t$ test) between levels in WT versus RNAi25::StMES1 silenced plants for each time point. 
sufficient accumulation of the MeSA signal following pathogen infection (Park et al. 2007). By contrast, SA-mediated inhibition of NtSABP2's MeSA esterase activity does not appear to be critical in the systemic leaves for two reasons. First, the free SA levels in the systemic tissue are too low to effectively inhibit NtSABP2's MeSA esterase activity (or StMES1's activity in potato). Second, expression in the systemic leaves of a mutated version of NtSABP2 that cannot bind and, thus, be inhibited by $\mathrm{SA}$ is able to complement the SAR-defective phenotype of $S A B P 2$-silenced tobacco. Based on these results, we anticipated that expression of StMES1syn in the systemic leaves of $S A B P 2$-silenced tobacco would restore SAR but not enhance SAR beyond that seen with NtSABP2syn.

In plants with high endogenous levels of SA, such as potato, it was previously suggested that SA-mediated SAR signaling is achieved via enhancing the sensitivity of the plant to SA (Yu et al. 1997; Navarre and Mayo 2004). One possible mechanism may involve the existence of a threshold level of free SA, which must be reached in order to induce defense responses. Under nonstress conditions, potato would maintain SA levels under this threshold level; after a biotic stress, SA levels would rise above this threshold to induce SAR or other defense responses. In agreement with this, Navarre and Mayo (2004) found that potato plants grown under optimal conditions are capable of expressing $P R-1$ in response to even low concentrations of SA. This suggests that potato is capable of tightly regulating free SA levels, which would allow the tissue to remain responsive to increases in free $\mathrm{SA}$ induced by pathogen attack or elicitor treatment. Consistent with this possibility, over $99.5 \%$ of the total SA in these plants was conjugated to glucose, while free SA levels were comparable to those found in tobacco and Arabidopsis. Our analysis using cv. Désirée similarly revealed that most of the SA is present in its glucoside form (SAG). The mechanism through which SA homeostasis is maintained may involve the interconversion of SA with its inactive forms, MeSA and SAG. We posit that, in WT plants, AA treatment induces rises in SA above this threshold in both the treated and upper untreated leaves and thereby activates $P R$ gene expression and SAR development. By contrast, SA levels in the upper untreated leaves of StMES1-silenced plants may not surpass this threshold at an early time after AA treatment ( $24 \mathrm{hpt}$ ); hence, $P R$ gene induction is delayed and weak and SAR does not develop despite a delayed increase in SA to near WT levels by $144 \mathrm{hpt}$. In the local AA-treated leaves, we suspect that the reduced level of SA in StMES1silenced plants is still sufficient to surpass the minimum threshold required for $P R$ gene expression and local (basal) resistance. The existence of a minimum threshold of $\mathrm{SA}$ required for defense responses was previously suggested by Liu and associates (2010), based on the finding that Arabidopsis plants constitutively overexpressing AtBSMT1, which converts SA into its inactive form MeSA, were compromised for PTI but not ETI. They proposed that infection with an avirulent pathogen induced sufficiently elevated levels of SA to surpass a minimum threshold, even though those levels were significantly lower than those found in WT plants.

Although StMES1 appears to be required for SAR, the observation that StMES1-silenced potato plants support levels of $P$. infestans growth similar to untreated WT plants suggests that StMES1 is not required for basal resistance. Similarly, basal resistance was not affected in Arabidopsis underexpressing AtMES genes (Vlot et al. 2008b). One possible explanation is that potato, like Arabidopsis, contains multiple $M E S$ gene homologs. In this scenario, different homolog may play distinct roles during SAR or basal defense responses in potato and Arabidopsis. Thus, if the silencing construct alters the expression of only a subset of $M E S$ genes, SAR could be dis- rupted (possibly to varying extents, as was observed in the 10 StMES1-silenced lines) without altering basal resistance. Currently, one StMES1 homolog has been identified from the potato EST database (clone BE924354). Because this gene shares high sequence homology at the nucleotide and amino acid levels with StMES1, we suspect that it encodes a protein with similar biochemical properties, including inhibition by tetraFA. The StMES1 silencing construct effectively silenced the expression of this putative homolog in the 10 StMES1silenced lines tested (Supplementary Fig. 3B). However, because the potato genome sequence is incomplete, we cannot rule out the possible existence of an unidentified homolog that plays a role in basal resistance (or SAR) and is not silenced by this construct. An alternative explanation for why basal resistance is unaffected by StMES1 silencing is that the detached leaflet assay used in this study might not be sensitive enough to detect changes in basal defense responses against $P$. infestans. $\mathrm{Yu}$ and associates (1997) could not detect any differences in the local tissue of WT or NahG transgenic potato after inoculation with $P$. infestans using this assay. However, Halim and associates (2007) reported that, although lesion sizes were comparable, significant differences in basal resistance against $P$. infestans could be detected in WT and NahG transgenic potato by measuring the amount of $P$. infestans biomass using quantitative (q)PCR and trypan blue staining of pathogen structures. Thus, we cannot rule out the possibility that StMES1 is involved in basal defenses against $P$. infestans.

AA was used as the SAR inducer in these studies because the potato $\mathrm{cv}$. Désirée does not contain any known $R$ genes conferring resistance to $P$. infestans. AA, which is the major fatty acid present in $P$. infestans infection structures, has been shown to act as a natural fungal elicitor (PAMP) in potato tubers. Similar to infection with an avirulent race of $P$. infestans, AA treatment induces several local responses, including a rapid increase in protein synthesis, synthesis of sesquiterpene phytoalexins, HR, lignifications, and induction of SAR (Varns et al. 1971; Cohen et al. 1991; Coquoz et al. 1995). These findings, combined with the observations that i) our AA-treated potato consistently displayed a twofold reduction in both lesion size and sporangia counts following a secondary infection with $P$. infestans and ii) $P$. infestans-induced SAR in potato corresponded with a two- to threefold reduction in lesion number (Strömberg and Brishammar 1991), strongly suggest that SAR induced by AA or pathogen treatment is comparable. Moreover, PTI induced by virulent pathogens or direct treatment with PAMPs have been shown to induce SAR in Arabidopsis (Mishina and Zeier 2007; Attaran et al. 2009) and potato (Strömberg and Brishammar 1991).

In addition to SAR, AA-treated WT potato exhibited increased levels of SA and MeSA and heightened $P R$ gene expression in the untreated leaves. Similar increases in SA, MeSA, and $P R$ gene expression have been associated with SAR development in tobacco and Arabidopsis (Park et al. 2007; Vlot et al. 2008b). It should be noted that the systemic $P R$ gene expression and SA accumulation observed in the upper untreated tissue of our AA-treated WT plants are not likely due to translocation of AA to the distal tissue, because Coquoz and associates (1995) did not detect acropetal transport of injected radiolabeled AA to distal tissue.

The results presented in this study, particularly the correlation between SA levels, $P R$ gene expression, and SAR development, conflict with those from other studies, which failed to detect any correlation between SA and SAR in potato (Coquoz et al. 1995; Yu et al. 1997). However, Yu and associates (1997) only monitored SA levels at $144 \mathrm{hpt}$ and, therefore, may have missed a critical earlier increase in the upper untreated tissues of AA-treated plants. Our analyses also failed to detect a sig- 
nificant difference in SA levels in the upper untreated leaves of mock or AA-treated plants at 144 hpt $(P=0.08)$ but a significant difference was detected at $24 \mathrm{hpt}(P=0.01)$. This finding, combined with the subsequent demonstration by Yu and associates (1997) that SA-deficient NahG potato are compromised for AA-induced SAR to $P$. infestans, strongly suggest that SA is a critical SAR signal in the upper untreated tissue. The reason for the discrepancy between our results and those of Coquoz and associates (1995) are less clear; however, it may arise from differences between the potato cultivars studied and/or environmental factors. Growth conditions have previously been shown to influence the ability of SA to induce $P R-1$ gene expression in potato (Navarre and Mayo 2004). In addition, recent studies in Arabidopsis have indicated that disease resistance and the extent of SA accumulation is heavily influenced by various environmental factors, including the time of day when SAR is induced (Griebel and Zeier 2008).

Although this study, combined with our analyses of tobacco and Arabidopsis, suggests that MeSA is a critical SAR signal, a recent study by Attaran and associates (2009) has questioned this conclusion. Using Arabidopsis containing a T-DNA knockout (KO) mutation in benzoic acid/salicylic acid carboxyl methyltransferase 1 (AtBSMT1), the enzyme primarily responsible for synthesis of MeSA from SA after pathogen attack, the authors reported that SAR was not impaired despite the loss of MeSA production. However, our analyses of a similar Atbsmt 1 KO mutant led to the opposite conclusion, because these plants displayed i) suppressed levels of MeSA in the primary infected leaves, ii) reduced levels of SA and SAG in the distal leaves, and iii) compromised SAR development (Liu et al. 2010). Moreover, the SAR-defective phenotype of Atbsmt1 was rescued by treatment with MeSA, and petiole exudates from the infected leaves of WT plants induced SAR in Atbsmt1, as well as WT recipient plants, whereas petiole or phloem exudates from infected Atbsmtl leaves did not induce SAR in either WT or Atbsmt1 recipient plants. Together, these results argue that $A t B S M T 1$ is required in the primary infected tissue to produce the mobile SAR signal and, thereby, support our model for $\mathrm{MeSA}$ as a SAR signal. The reason for the discrepancy between our results and those of Attaran and associates (2009) are likely due to different experimental conditions used for SAR assessment (Liu et al. 2010). SAR development is a complex process that involves multiple factors, including several defense phytohormones, several mobile signals (Vlot et al. 2008a), one or more environmental factors (Zeier et al. 2004; Griebel and Zeier 2008), and plant maturity (Cameron and Zaton 2004).

In addition to MeSA, it is important to note the extensive evidence, particularly from studies in Arabidopsis, indicating the involvement of a lipid or lipid-derived mobile SAR signal (Maldonado et al. 2002; Nandi et al. 2004; Truman et al. 2007; Chaturvedi et al. 2008; Jung et al. 2009). JA, which plays an important role in defenses against necrotrophic pathogens and insect attack, also has been implicated in SAR signaling (Truman et al. 2007). In potato, AA elicits the activity of a lipoxygenase in tubers and potato callus, which might release fatty acids from the plasma membrane for conversion to JA (Bostock et al. 1992; Vaughn and Lulai 1992). Cohen and associates (1993) showed that treatment of potato and tomato with JA led to local and systemic protection against $P$. infestans. Recently, Halim and associates (2009) showed that SA and JA are both required for PAMP-induced defense responses in potato. Moreover, their data suggest that SA and JA act in the same signaling pathway in potato treated with the $P$. infestansderived PAMP Pep-13; they also showed that SA accumulation is upstream of JA accumulation. Future studies will be required to determine whether MeSA acts in concert with other pro- posed signals, including JA (Halim et al. 2009), to activate SAR in AA-treated potato. However, the results from this study suggest that it is possible to extrapolate the results obtained from tobacco and Arabidopsis to model SAR in important crop species that contain high endogenous levels of SA, such as potato. This opens the possibility of using SAR as a strategy to improve broad-spectrum resistance in potato against devastating diseases, such as potato late blight, by manipulating the levels of MeSA and SA.

\section{MATERIALS AND METHODS}

\section{Plant material and growth conditions.}

Nicotiana tabacum (tobacco) cv. Xanthi-nc (NN) plants, $S A B P 2$-silenced tobacco 1-2 line (Park et al. 2007), and $S A B P 2$-silenced tobacco carrying XVE::AtMES9syn (Vlot et al. 2008b) were grown in a growth chamber with a 14-h day cycle $\left(110 \mu \mathrm{mol} \mathrm{m} \mathrm{m}^{-2} \mathrm{~s}^{-1}\right)$ at $22^{\circ} \mathrm{C}$ and approximately $60 \%$ relative humidity. $S$. tuberosum L. cv. Désirée (R0) potato plants were propagated in vitro on rooting-inducing media (Van Eck et al. 2007) and transferred after 15 to 21 days to pots in the growth chamber. Potato plants were grown in the growth chamber under the same conditions as tobacco plants for 5 weeks. Potato plants were transferred to a greenhouse for 1 week before AA treatment and SAR experiments.

\section{DNA constructs.}

To identify the putative ortholog of tobacco SABP2, we used the full-length cDNA sequence of the tobacco $S A B P 2$ (GenBank no. AY485932) (Kumar and Klessig 2003) as a translated nucleotide query to perform tBLASTx searches against the translated nucleotide potato ( $S$. tuberosum) EST database of the National Center for Biotechnology Information and The Institute for Genomic Research. FGENE-SH was used to predict the protein sequence encoded by the nucleotide information gained from this study. Nucleic acid and protein sequence alignments were done using the Clustal W2 program (Larkin et al. 2007) in the European Bioinformatic Institute interface. One potato EST (GenBank no. CK270870.1) was selected for further analysis based on sequence similarity with tobacco $S A B P 2$. A full-length cDNA for StMES1 was amplified from potato leaf cDNA using $P f u$ native DNA polymerase, a proofreading DNA polymerase, following the vendor recommendations (Stratagene, La Jolla, CA, U.S.A.) using a forward primer containing the HindIII recognition site 5'AAGCTTATGGAGGTTATGAAGAAACACTTTG-3' and a reverse primer containing the $X h o$ I recognition site $5^{\prime}$-CTCGA GATTGTATTTATGGGCAATCTCCAAG-3' for further cloning purposes. PCR was set as follows: $94^{\circ} \mathrm{C}$ for $4 \mathrm{~min}$; followed by 35 cycles at $94^{\circ} \mathrm{C}$ for $30 \mathrm{~s}, 50^{\circ} \mathrm{C} 30 \mathrm{~s}$, and $72^{\circ} \mathrm{C}$ for $1 \mathrm{~min} 30 \mathrm{~s}$; and a final extension at $72^{\circ} \mathrm{C}$ for $5 \mathrm{~min}$. The PCR product was separated on an agarose gel; DNA from the excised band was purified using a QIA-quick Gel Extraction Kit (Qiagen, Valencia, CA, U.S.A.) and subjected to dATP-tail amplification before cloning into the pGEM-T Easy Vector (Promega Corp., Madison, WI, U.S.A.). After sequencing, the StMES1 cDNA was digested with HindIII and XhoI and cloned in the expression vector pET-21dC for protein expression. A cDNA encoding StMES1syn was designed and synthesized by DNA2.0 Inc. (Menlo Park, CA, U.S.A.) as previously described (Kumar et al. 2006; Vlot et al. 2008b). The StMES1syn construct, which contains the XhoI and SpeI recognition sites at the $5^{\prime}$ and $3^{\prime}$ ends, respectively, and a nucleotide sequence encoding a C-terminal myc tag were cloned into the pER8 vector (pER8::StMES1syn) using XhoI and SpeI. For genesilencing assays, the first 473 bp of StMES1 was cloned into pHANNIBAL (Wesley et al. 2001) in sense and antisense ori- 
entations. The sense and antisense fragments were previously cloned in pGEMT-easy and sequenced. The sense fragment was amplified using StSABP2XhoI-forward 5'-CTCGAGAT GGAGGTTATGAAGAAACACTTTG-3' and StSABP2EcoRIreverse 5'-GAATTCGCCAAGAACTTGGGCCCAAAAAGC$3^{\prime}$; the antisense fragment was amplified using StSABP2XbaIforward 5'-TCTAGAATGGAGGTTATGAAGAAACACTTTG$3^{\prime}$ and StSABP2ClaI-reverse 5'-ATCGATGCCAAGAACTTG GGCCCAAAAAGC-3'. The PCR conditions were the same as indicated above. The StMES1 cassette from pHANNIBAL was transferred to the binary vector pART27 (Gleave 1992) using NotI (pART27::StMES1) for Agrobacterium spp. transformation.

\section{Protein expression, enzyme activity, and inhibition assays.}

The pET21dC-StMES1 construct was used to transform $E$. coli BL21 for protein expression. Protein expression was induced overnight at $18^{\circ} \mathrm{C}$ using $0.1 \mathrm{mM}$ isopropyl-thio-galactopyranoside. His $_{6}$-tagged recombinant protein was purified using $\mathrm{Ni}^{2+}$-NTA resin (Novagen, Madison, WI, U.S.A.) following the manufacturer's instructions. MeSA esterase activity was measured using a two-step radiochemical esterase assay (Forouhar et al. 2005; Park et al. 2009) using $0.6 \mu \mathrm{g}$ of purified StMES1 protein and $0.1 \mathrm{mM}$ MeSA. Kinetic parameters were calculated using increasing concentrations of MeSA (5 to 500 $\mu \mathrm{M})$ with $2.5 \mathrm{nmol}{ }^{14} \mathrm{C}$-S-adenosylmethionine and $10 \mu \mathrm{g}$ of recombinant Clarkia breweri SA carboxyl methyl transferase. The Lineweaver-Burk plot used to calculate the $K_{m \text { mapp }}$ and $V_{\text {max }}$ values was generated using SigmaPlot. In vitro inhibition of MeSA esterase activity by SA or tetraFA (Rieke Metals, Inc., Lincoln, NE, U.S.A.) was done as described by Park and associates (2009). Briefly, enzyme activities were determined using $0.4 \mu \mathrm{g}$ of purified protein and 5 to $1,000 \mu \mathrm{M}$ MeSA as substrate with the addition of either SA (1 to $50 \mu \mathrm{M})$ or tetraFA ( 0.01 to $1 \mathrm{mM})$. Global Fitting analysis was used to simultaneously fit all data to the equation for competitive inhibition using SigmaPlot. $\mathrm{IC}_{50}$ was calculated by plotting the log of the tetraFA concentration $(\mu \mathrm{M})$ versus velocities expressed as percentage of the initial velocity in the absence of the inhibitor, and fitting the values for linear regression.

\section{Plant transformations.}

pER8::StMES1syn and pART27::StMES1 constructs were transformed into Agrobacterium tumefaciens LBA4404 (Invitrogen, Carlsbad, CA, U.S.A.) by electroporation. The Agrobacterium strain containing the $\mathrm{pER} 8:$ :StMES1 syn construct was used to transform leaf discs of $S A B P 2$-silenced tobacco (Kumar and Klessig 2003); transformation and regeneration of tobacco transgenics were done as described by Shah and Klessig (1996). Positive tobacco transformants were maintained and propagated by tissue culture on tobacco rooting media containing hygromycin at $8 \mathrm{mg} / \mathrm{liter}$ and carbenicillin at $250 \mathrm{mg} / \mathrm{liter}$.

The Agrobacterium strain containing the silencing construct pART27::StMES1 was used to transform potato Désirée internode segments following the protocol described by Van Eck and associates (2007). Briefly, potato explants from 6-week-old in vitro-grown plants were incubated for $10 \mathrm{~min}$ with a suspension of the Agrobacterium sp. (optical density at $600 \mathrm{~nm}=0.6$ to 0.7). After incubation, the explants were blotted dry with paper towels and transferred into a callus induction media for $48 \mathrm{~h}$ at $19^{\circ} \mathrm{C}$ in the dark. After incubation, explants were transferred to a selective plant regeneration media containing kanamycin (50 $\mathrm{mg} / \mathrm{liter}$ ) and carbenicillin (500 $\mathrm{mg} / \mathrm{liter}$ ); regenerated shoots were excised and transferred to a selective rooting media containing kanamycin (25 mg/liter) and carbenicillin (500 mg/liter). After three rounds of selection with the appropriate antibiotics, these transgenic potato were maintained and propagated in rooting media without antibiotics.
SAR induction and pathogen experiments.

Complementation analysis using the XVE::StMES1syn construct (pER8::StMES1syn) in tobacco was performed as reported (Kumar et al. 2006; Vlot et al. 2008b). Tobacco plants, 6 weeks after sowing (tobacco cv. Xanthi-nc, $S A B P 2$-silenced tobacco, or $S A B P 2$-silenced tobacco carrying XVE::AtMES9syn) or after transfer to soil from tissue culture (pER8::StMES1syn), were induced for SAR by mechanical inoculation with TMV onto three lower leaves per plant using Carborundum as abrasive. Two leaf discs were collected before inoculation $\left(\mathrm{T}_{0}\right)$ from each plant for RNA analysis. One day after primary infection, two upper uninoculated leaves were sprayed with $30 \mu \mathrm{M} \beta$ estradiol in $0.01 \%$ Tween-20 for induction of the AtMES9syn and StMES1syn transgene expression. At 1 and 6 days after $\beta$-estradiol treatment, leaf discs were collected from each plant for RNA analysis. At 7 days after primary TMV infection, the upper $\beta$-estradiol-treated leaves were challenged by a primary TMV infection. Lesion sizes were measured with a digital Vernier caliper 5 days after primary or secondary TMV infection.

SAR was induced in 6-week-old potato plants in the greenhouse by spraying a sonicated AA suspension $(1.5 \mathrm{mg} / \mathrm{ml}[5$ $\mu \mathrm{M}]$ ) (Sigma, St. Louis) on the surface of three lower leaves as described by Yu and associates (1997). Six days after AA treatment, upper untreated leaflets were detached and challenged with $P$. infestans using a detached leaflet assay (Liu et al. 1994; Yu et al. 1997). Isolate US-11 of $P$. infestans was grown on rye $\mathrm{B}$ agar at $15^{\circ} \mathrm{C}$ and the oomycete sporangia were harvested by washing the plates with sterilized water. Sporangia number was counted using a hemacytometer and the suspension was adjusted to 5,000 sporangia/ml and incubated for $3 \mathrm{~h}$ at $4{ }^{\circ} \mathrm{C}$ for zoospore release; $20 \mu \mathrm{l}$ of this suspension was dropped onto the center of the abaxial leaflet surface. The inoculated leaflets were kept in petri dishes containing $1.5 \%$ water agar and incubated at $15^{\circ} \mathrm{C}$. Blighted area was measured at 5 days postinoculation (dpi) and sporangia numbers were count at 7 dpi.

For tetraFA inhibition of SAR in potato, AA-mediated SAR induction was done as described above. At $24 \mathrm{hpt}$ with AA, upper untreated leaves were sprayed with $10 \mathrm{mM}$ HEPES, $\mathrm{pH}$ 7.0, without (control) or with $20 \mathrm{mM}$ tetraFA; this treatment was continued every $24 \mathrm{~h}$ for the next 5 days. SAR was assessed using the detached leaflet assay as described above.

\section{MeSA, SA, and SAG quantification.}

WT and StMES1-silenced potato were treated with AA to induce SAR as described above. Tissue was collected at 0, 24, and 144 hpt with AA from one of the three treated leaves (water or AA) and from the untreated leaf located right above using two potato plants/genotype/treatment/time points for MeSA, SA, SAG, and $P R$ gene expression profile analysis. For MeSA analysis, approximately $120 \mathrm{mg}$ of tissue was collected and MeSA content was measured using gas chromatographymass spectrometry (CP-3800/Quadrupode-1200L system; Varian, Sunnyvale, CA, U.S.A.) as described before (Park et al. 2007, 2009). For SA and SAG analysis, approximately $350 \mathrm{mg}$ of tissue was collected as described above, and was quantified using high-performance liquid chromatography analysis on an ARH-601 organic acid column (100 by $6.5 \mathrm{~mm}$; Transgenomic, Inc., Omaha, NE, U.S.A.) run at $55^{\circ} \mathrm{C}$ using a $0.01 \mathrm{~N}$ solution of $\mathrm{H}_{2} \mathrm{SO}_{4}$ as a solvent with a flow rate of $0.6 \mathrm{ml} / \mathrm{min}$ as described by Park and associates (2007).

\section{RNA analysis.}

Total RNA was isolated from two leaf discs from tobacco or potato plants using TRIzol reagent (Invitrogen) following the manufacturer's instructions. After treatment with RNase-free 
DNase (RQ1; Promega Corp.), the RNA was subjected to a second TRIzol extraction and used for RT reactions. cDNA was synthesized using the Super-Script II reverse transcriptase kit (Invitrogen) and amplified using primers outlined in Supplementary Table 2. Control reactions to normalize RT-PCR amplifications were run with the primers derived from the constitutively expressed translation elongation factor $1 \alpha$ gene.

\section{ACKNOWLEDGMENTS}

We thank all the members in W. E. Fry's lab, especially P. Zuluaga, for helping with the $P$. infestans infections; the members of the BTI plant transformation facility; and D. Dempsey for critically reading the manuscript. This work was funded by National Science Foundation grants IOS0525360 and IOS-0820405 to D. F. Klessig and a grant from the Protein Structure Initiative of the National Institutes of Health (U54 GM074958) to NESG.

\section{LITERATURE CITED}

Attaran, E., Zeier, T. E., Griebel, T., and Zeier, J. 2009. Methyl salicylate production and jasmonate signaling are not essential for systemic acquired resistance in Arabidopsis. Plant Cell 21:954-971.

Bostock, R. M., Yamamoto, H., Choi, D., Ricker, K. E., and Ward, B. L. 1992. Rapid stimulation of 5-lipoxygenase activity in potato by the fungal elicitor arachidonic acid. Plant Physiol. 100:1448-1456.

Cameron, R. K., and Zaton, K. 2004. Intercellular salicylic acid accumulation is important for the age-related resistance response to Pseudomonas syringae. Physiol. Mol. Plant Pathol. 65:197-209.

Chaturvedi, R., Krothapalli, K., Makandar, R., Nandi, A., Sparks, A. A., Roth, M. R., Welti, R., and Shah, J. 2008. Plastid $\omega 3$-fatty acid desaturase-dependent accumulation of a systemic acquired resistance inducing activity in petiole exudates of Arabidopsis thaliana is independent of jasmonic acid. Plant J. 54:106-117.

Chisholm, S. T., Coaker, G., Day, B., and Staskawicz, B. J. 2006. Host-microbe interactions: Shaping the evolution of the plant immune response. Cell 124:803-814.

Cohen, Y., Gisi U., and Mösinger, E. 1991. Systemic resistance of potato plants against Phytophthora infestans induced by unsaturated fatty acids. Physiol. Mol. Plant Pathol. 38:255-263.

Cohen, Y., Gisi, U., and Niderman, T. 1993. Local and systemic protection against Phytophthora infestans induced in potato and tomato plants by jasmonic acid and jasmonic methyl ester. Phytopathology 83:10541062

Coquoz, J. L., Buchala, A. J., Meuwly, P., and Métraux, J. P. 1995. Arachidonic acid induces local but not systemic synthesis of salicylic acid and confers systemic resistance in potato plants to Phytophthora infestans and Alternaria solani. Biochem. Cell Biol. 85:1219-1224.

Dempsey, D., Shah, J., and Klessig, D. F. 1999. Salicylic acid and disease resistance in plants. Crit. Rev. Plant Sci. 18:547-575.

Du, H., and Klessig, D. F. 1997. Identification of a soluble, high affinity salicylic acid-binding protein in tobacco. Plant Physiol. 113:1319-1327.

Durrant, W. E., and Dong, X. 2004. Systemic acquired resistance. Annu. Rev. Phytopathol. 42:185-209.

Forouhar, F., Yang, Y., Kumar, D., Chen, Y., Fridman, E., Park, S. W., Chiang, Y., Acton, T. B., Montelione, G. T., Pichersky, E., Klessig, D. F., and Tong, L. 2005. Structural and biochemical studies identify tobacco SABP2 as a methyl salicylate esterase and implicate it in plant innate immunity. Proc. Natl. Acad. Sci. U.S.A. 102:1773-1778.

Glazebrook, J. 2005. Contrasting mechanisms of defense against biotrophic and necrotrophic pathogens. Annu. Rev. Phytopathol. 43:205-227.

Gleave, A. 1992. A versatile binary vector system with a T-DNA organizational structure conducive to efficient integration of cloned DNA into a plant genome. Plant Mol. Biol. 20:1203-1207.

Greenberg, J. T., and Yao, N. 2004. The role and regulation of programmed cell death in plant-pathogen interactions. Cell Microbiol. 6:201-211.

Griebel, T., and Zeier, J. 2008. Light regulation and daytime dependency of inducible plant defenses in Arabidopsis: Phytochrome signaling controls systemic acquired resistance rather than local defenses. Plant Physiol. 147:790-801.

Halim, V., Eschen-Lippold, L., Altmann, S., Birschwilks, M., Scheel, D., and Rosahl, S. 2007. Salicylic acid is important for basal defense of Solanum tuberosum against Phytophthora infestans. Mol. Plant-Microbe Interact. 11:1346-1352.

Halim, V., Altmann, S., Ellinger, D., Eschen-Lippold, L., Miersch, O., Scheel, D., and Rosahl, S. 2009. PAMP-induced defense responses in potato required both salicylic acid and jasmonic acid. Plant J. 57:230-242.
Jones, J. D. G., and Dangl, J. L. 2006. The plant immune system. Nature 444:323-329

Jung, H. W., Tschaplinski, T., Wang, L., Glazebrook, J., and Greenberg, J. T. 2009. Priming in systemic plant immunity. Science 324:89-91.

Kombrink, E., Büchter, R., Wegener, S., and Scheel, D. 1996. Systemic acquired resistance in potato. Pages 483-491 in: Modern Fungicides and Antifungal Compounds. H. Lyr, P. E. Russell, and H. D. Sisler, eds. Intercept, Andover.

Kumar, D., and Klessig, D. F. 2003. The high affinity salicylic acid-binding protein 2 is required for plant innate immunity and has salicylic acid-stimulated lipase activity. Proc. Natl. Acad. Sci. U.S.A. 100:16101-16106.

Kumar, D., Gustafsson, C., and Klessig, D. F. 2006. Validation of RNAi silencing specificity using synthetic genes: Salicylic acid-binding protein 2 is required for plant innate immunity. Plant J. 45:863-868.

Larkin, M. A., Blackshields, G., Brown, N. P., Chenna, R., McGettigan, P. A., McWilliam, H., Valentin, F., Wallace, I. M., Wilm, A., Lopez, R., Thompson, J. D., Gibson, T. J., and Higgins, D. G. 2007. Clustal W and Clustal X version 2.0. Bioinformatics 23:2947-2948.

Liu, D., Raghothama, K. G., Hasegawa, P. M., and Bressan, R. A. 1994. Osmotin overexpression in potato delays development of disease symptoms. Proc. Natl. Acad. Sci. U.S.A. 91:1888-1892.

Liu, P. P., Yang Y., Pichersky, E., and Klessig, D. F. 2010. Altering expression of benzoic acid/salicylic acid carboxyl methyltransferase 1 compromises systemic acquired resistance and PAMP-triggered immunity in Arabidopsis. Mol. Plant-Microbe Interact. 23:82-90.

Malamy, J., Carr, J. P., Klessig, D. F., and Raskin, I. 1990. Salicylic acid: A likely endogenous signal in the resistance response of tobacco to viral infection. Science 250:1002-1004.

Maldonado, A. M., Cameron, R. K., Doernert, P., Dixon, R. A., and Lamb, C. 2002. A putative lipid transfer protein involved in systemic resistance signaling in Arabidopsis. Nature 419:399-403.

Métraux, J. P., Signer, H., Ryals, J., Ward, E., Wyss-Benz, M., Gaudin, J., Raschdorf, K., Blum, W., and Inverardi, B. 1990. Increase in salicylic acid at the onset of systemic acquired resistance in cucumber. Science 250:1004-1006.

Mishina, T. E., and Zeier, J. 2007. Pathogen-associated molecular pattern recognition rather than development of tissue necrosis contributes to bacterial induction of systemic acquired resistance in Arabidopsis. Plant J. 50:500-513.

Nandi, A., Welti, R., and Shah, J. 2004. The Arabidopsis thaliana dihydroxyacetone phosphate reductase gene SUPPRESSOR OF FATTY ACID DESATURASE DEFICIENCY 1 is required for glycerolipid metabolism and for the activation of systemic acquired resistance. Plant Cell 16:465-477.

Navarre, D. A., and Mayo, D. 2004. Differential characteristics of salicylic acid-mediated signaling in potato. Physiol. Mol. Plant Pathol. 64:179188.

Park, S. W., Kaimoyo, E., Kumar, D., Mosher, S., and Klessig, D. F. 2007. Methyl salicylate is a critical mobile signal for plant systemic acquired resistance. Science 318:113-116.

Park, S. W., Liu, P. P., Forouhar, F., Vlot, A. C., Tong, L., Tietjen, K., and Klessig, D. F. 2009. Use of a synthetic salicylic acid analog to investigate the roles of methyl salicylate and its esterases in plant disease resistance. J. Biol. Chem. 284:7307-7317.

Raskin, I. 1992. Role of salicylic acid in plants. Annu. Rev. Plant Physiol. Plant Mol. Biol. 43:439-463.

Schröder, M., Hahlbrock, K., and Kombrink, E. 1992. Temporal and spatial patterns of 1,3- $\beta$-glucanase and chitinase induction in potato leaves infected by Phytophthora infestans. Plant J. 2:161-172.

Shah, J., and Klessig, D. F. 1996. Identification of a salicylic acid-responsive element in the promoter of the tobacco pathogenesis-related $\beta-1,3-$ glucanase gene, PR2d. Plant J. 10:1089-1101.

Silverman, P., Seskar, M., Kanter, D., Schweizer, P., Metraux, J. P., and Raskin, I. 1995. Salicylic acid in rice. Biosynthesis, conjugation, and possible role. Plant Physiol. 108:633-639.

Strömberg, A., and Brishammar, S. 1991. Induction of systemic resistance in potato (Solanum tuberosum L.), plants to late blight by local treatment with Phytophthora infestans (Mont.) de Bary, Phytophthora cryptogea Pethyb. \& Laff., or dipotassium phosphate. Potato Res. 34:219225.

Truman, W., Bennett, M., Kubigsteltig, I., Turnbull, C., and Grant, M. 2007. Arabidopsis systemic immunity uses conserved defense signaling pathways and is mediated by jasmonates. Proc. Natl. Acad. Sci. U.S.A. 104:1075-1080.

Van Eck, J., Conlin, B., Garvin, D. F., Mason, H., Navarre, D. A., and Brown, C. R. 2007. Enhancing beta-carotene content in potato by RNAi-mediated silencing of the beta-carotene hydroxylase gene. Am. J. Potato Res. 84:331-342.

Varns, J. L., Kué, J., and Williams, E. B. 1971. Terpenoid accumulation as 
a biochemical response of the potato tuber to Phytophthora infestans. Phytopathology 61:174-177.

Vaughn, S. F., and Lulai, E. C. 1992. Further evidence that lipoxygenase activity is required for arachidonic acid-elicited hypersensitivity in potato callus cultures. Plant Sci. 84:91-98.

Vernooij, B., Friedrich, L., Morse, A., Reist, R., Kolditz-Jawhar, R., Ward, E., Uknes, S., Kessmann, H., and Ryals, J. 1994. Salicylic acid is not the translocated signal responsible for inducing systemic acquired resistance but is required in signal transduction. Plant Cell 6:959-965.

Vlot, A. C., Klessig, D. F., and Park, S. W. 2008a. Systemic acquired resistance: The elusive signal(s). Curr. Opin. Plant Biol. 11:436-442.

Vlot, A. C., Liu, P. P., Cameron, R. K., Park, S. W., Yang, Y., Kumar, D., Zhou, F., Padukkavidana, T., Gustafsson, C., Pichersky, E., and Klessig, D. F. 2008b. Identification of likely orthologs of tobacco salicylic acidbinding protein 2 and their role in systemic resistance in Arabidopsis thaliana. Plant J. 56:445-456.

Vlot, A. C., Dempsey, D., and Klessig. D. F. 2009. Salicylic acid, a multifaceted hormone to combat disease. Annu. Rev. Phytopathol. 47:177206.

Wesley, S. V., Helliwell, C. A., Smith, N. A, Wang, M., Rouse, T., Liu, Q., Gooding, P., Singh, S., Abbott, D., Stoutjesdijk, P., Robinson, S., Gleave, A., Green, A., and Waterhouse, P. 2001. Construct design for efficient, effective and high-throughput gene silencing in plants. Plant J. 27:581-590.

Yu, D., Liu, Y., Fan, B., Klessig, D. F., and Chen, Z. 1997. Is the high basal level of salicylic acid important for disease resistance in potato? Plant Physiol. 115:343-349.

Zhao, N., Guan, J., Forouhar, F., Tchaplinski, T., Cheng, Z. M., Tong, L. and Chen, F. 2009. Two poplar methyl salicylate esterases display comparable biochemical properties but divergent expression patterns. Phytochemistry 70:32-39.

Zeier, J., Pink, B., and Muller, M. J. 2004. Light conditions influence specific defense responses in incompatible plant-pathogen interactions: Uncoupling systemic resistance from salicylic acid and $P R-1$ accumulation. Planta 219:673-683.

Zuo, J., Niu, Q.-W., and Chua, N. 2000. An estrogen receptor-based transactivator XVE mediates highly inducible gene expression in transgenic plants. Plant J. 24:265-273.

\section{AUTHOR-RECOMMENDED INTERNET RESOURCES}

National Center for Biotechnology Information tBLASTx server: www.ncbi.nlm.nih.gov/BLAST/Blast.cgi

Softberry's FGENE-SH server: www.softberry.com/berry.phtml 